\title{
COMPARISON OF INTRATHECAL HYPERBARIC ROPIVACAINE 0.5\% WITH AND WITHOUT 75 MG MAGNESIUM SULFATE AS AN ADJUVANT FOR INFRA UMBILICAL SURGERIES: A DOUBLE-BLIND RANDOMIZED CLINICAL TRIAL
}

\author{
SRINIDHI SRIKANTH, ANTONY JOHN CHARLES S*, KAMESHWAR YV, GAYATRI MISHRA
}

Department of Anaesthesiology, Mahatma Gandhi Medical College and Research Institute, Sri Balaji Vidyapeeth Deemed to be University, Pillayarkuppam, Puducherry, India. Email: anjocharlie@gmail.com

Received: 20 June 2021, Revised and Accepted: 03 August 2021

\section{ABSTRACT}

Objective: Intrathecal magnesium as an adjuvant to hyperbaric ropivacaine could extend duration of sensory blockade and improve the quality of post-operative analgesia; thereby reducing opioid requirements and its adverse effects. Hence, we conducted this prospective, randomized, doubleblind clinical trial to observe its effects for day care surgeries.

Methods: After obtaining institutional ethical committee approval and registration of trial, patients' informed consent was taken and eighty adult patients of either gender, ASA 1 and 2, posted for infra umbilical surgeries were divided into two groups: Group RM received 3 ml hyperbaric Ropivacaine with $0.75 \mathrm{ml}$ magnesium sulfate $(75 \mathrm{mg}$ ) and Group R received $3 \mathrm{ml}$ hyperbaric Ropivacaine with $0.75 \mathrm{ml}$ sterile water. Sensory and motor blockade parameters, hemodynamic variables, and adverse effects were monitored, analyzed using appropriate statistical tests.

Results: Total duration of sensory blockade was significantly prolonged in Group RM compared to Group R (242.8 \pm 9.9 versus $186.6 \pm 8.4$ min) $\left({ }^{* * *} \mathrm{p}<0.001\right)$. Complete motor regression was observed significantly earlier in Group RM than in Group R $(151.3 \pm 7.8$ versus $184.7 \pm 5.6 \mathrm{~min})\left({ }^{*} \mathrm{p}<0.05\right)$. Post-operative pain free interval was significantly prolonged in group RM compared to group R (725.2 \pm 18.6 vs. $515.2 \pm 17.8 \mathrm{~min})$ ( $\left.{ }^{* * *} \mathrm{p}<0.001\right)$.

Conclusion: We concluded that intrathecal magnesium as an adjuvant to hyperbaric Ropivacaine significantly prolonged both sensory blockade duration, post-operative pain-free interval without increasing motor blockade duration and the incidence of adverse effects.

Keywords: Intrathecal magnesium sulfate, Intrathecal hyperbaric ropivacaine, Day care anesthesia.

(c) 2021 The Authors. Published by Innovare Academic Sciences Pvt Ltd. This is an open access article under the CC BY license (http://creativecommons.org/ licenses/by/4.0/) DOI: http://dx.doi.org/10.22159/ajpcr.2021v14i9.42497. Journal homepage: https://innovareacademics.in/journals/index.php/ajpcr

\section{INTRODUCTION}

Spinal anesthesia is a preferred technique for day-care orthopedic, gynecological, and lower abdominal surgical procedures [1]. Lignocaine was commonly used due to its short duration of action but reports of transient radicular irritation led to decline in its use [2]. Intrathecal Ropivacaine offers shorter motor blockade duration hence, encouraging early mobilization in patients [3-5]. Due to difficulty in maintaining pharmacological stability of hyperbaric Ropivacaine, presently only isobaric solution is available. But Ropivacaine, made hyperbaric with Dextrose, had produced more consistent block, prolonged the needed duration with quicker complete regression $[6,7]$.

Opioid adjuvants have been used with intrathecal Ropivacaine for extending the duration of block and their side effects such as nausea, vomiting, pruritus, and sedation have been noted $[8,9]$. Intrathecal magnesium has been used in humans since 1906 [10,11].

Comparison of hyperbaric Ropivacaine, which is emerging as local anesthetic of choice for spinal anesthesia in day care surgery [2] with and without magnesium sulfate alone; is elucidated in fewer studies. Hence, we conducted this randomized trial to demonstrate its effects as an adjuvant to intrathecal hyperbaric Ropivacaine for day care infra umbilical surgeries by monitoring block characteristics, hemodynamic parameters, and adverse effects.

\section{METHODS}

This present prospective, randomized, and double-blind clinical trial was conducted in a tertiary care teaching hospital from January 2019 to
June 2020 after obtaining Institutional Ethics Committee approval and registration in Clinical Trials Registry of India.

80 adult patients (18-60 years) of either gender, American Society of Anesthesiologists Grade 1 and 2, posted for infra umbilical procedures under orthopedics, gynecology, urological, and general surgeries of approximately 2-h duration were included in the study. Patients unwilling to participate, pregnant and breast-feeding mothers, patients with spinal deformity, instrumentation or any contraindications for spinal anesthesia and patients with major cardiac, neurological, and respiratory illness were excluded from the study.

Selected patients underwent pre-anesthetic checkup and were informed about the aim of our study, familiarized with visual analogue scale (VAS) (0 - no pain to 10 - worst ever imaginable pain) in their local language, and a written informed consent was taken after ensuring their willingness to participate in the study.

Patients were kept Nil by mouth from 10 pm the day before surgery. Tablet Ranitidine $150 \mathrm{mg}$, Tablet Metoclopromide $10 \mathrm{mg}$, and Tablet Alprazolam $0.25 \mathrm{mg}$ were given with sips of water on the night before and at $7 \mathrm{am}$ on the morning of surgery. After taking patient inside the operation theatre, monitors were attached and baseline electrocardiogram, blood pressure, and $\mathrm{SpO} 2$ were noted. A wide bore intravenous (IV) line was secured with 18Gauge (G) IV cannula, and the fluid Ringer lactate infused at the rate of $10 \mathrm{ml} / \mathrm{kg} / \mathrm{h}$.

Patients were selected through simple random sampling using computer generated numbers and group allocation was done through sealed envelope technique. Patients were divided into two groups: 
Group R received $3 \mathrm{ml} 0.5 \%$ hyperbaric Ropivacaine with $0.75 \mathrm{ml}$ of

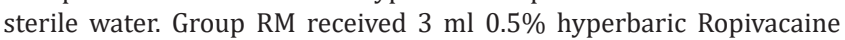
with $0.75 \mathrm{ml}$ of Magnesium Sulfate solution (75 mg). The total volume accounted to $3.75 \mathrm{ml}$ in both the groups. The drug preparation was intrathecally administered. Injection Ropivacaine was from brand Neon ROPIN $0.75 \%$ perseverative free preparation.

Both the preparations were checked and validated by the Dip stick method in our institute's central laboratory due to non-availability of the Densitometer while designing the study. The specific gravities were found comparable [12].

After placing the patient in sitting position, an assistant supported the patient, and the subarachnoid block was performed under aseptic precautions through midline approach at $\mathrm{L}_{3}$. $\mathrm{L}_{4}$ intervertebral space using a 25Gauge (G) Quincke spinal needle. Hyperbaric Ropivacaine solution was prepared aseptically (by an anesthetist who was not an investigator) just before injection by adding $1 \mathrm{ml}$ of $25 \%$ Dextrose to $2 \mathrm{ml}$ preservative free isobaric $0.75 \%$ Ropivacaine and $0.75 \mathrm{ml}(75 \mathrm{mg}$ ) preservative free Magnesium Sulfate solution (prepared by diluting $1 \mathrm{~g}$ (gm) of preservative free Magnesium sulfate with $10 \mathrm{ml}$ Normal Saline) or $0.75 \mathrm{ml}$ of sterile water available in ampoules. Once a free flow of cerebrospinal fluid (CSF) was obtained, the study drug was injected.

Patient was placed in the supine position immediately after injection and block parameters were recorded by an investigator who was blinded to the study drugs by pin prick method using a 26G blunted bevel-end of hypodermic needle, checked in mid axillary line with the patient's eyes covered. Onset of sensory blockade (defined as time between injection of drug to loss of sensation to pin prick at $\mathrm{T}_{2}$ level), level of sensory blockade, the time taken to achieve it, and time taken for regression to $\mathrm{T}_{10}$ and $\mathrm{S}_{2}$ level (total duration of sensory blockade) the onset and time taken for maximum motor blockade was assessed by James modification of Bromage scale and the total duration were all recorded. Heart rate (bpm), systolic blood pressure (SBP) and diastolic blood pressures ( $\mathrm{mm}$ of $\mathrm{Hg}$ ) were noted every $2 \mathrm{~min}$ for the first $10 \mathrm{~min}$, then for every 5 min till the sensory level fixation, after which it was noted for every $15 \mathrm{~min}$ till regression to $\mathrm{T}_{10}$ level and later every $30 \mathrm{~min}$ interval till the complete regression.

Surgery commenced after the establishment of $\mathrm{T}_{10}$ level sensory blockade. Duration of analgesia was defined as duration between spinal needle removal to requirement of first analgesia. Post-operative VAS at $3,6,9,12,18$, and $24 \mathrm{~h}$ was assessed and patients with VAS $\geq 4$ received Inj. Tramadol $1 \mathrm{mg} / \mathrm{kg}$ IV (maximum $400 \mathrm{mg}$ in $24 \mathrm{~h}$ in divided doses) and total 24-h analgesia consumption was noted. Complications, namely, Bradycardia defined as (PR $<50 \mathrm{bpm}$ or Fall in PR $>20 \%$ from baseline value was treated with IV Inj. Atropine $0.6 \mathrm{mg}$. Hypotension (SBP $<80 \mathrm{~mm}$ of $\mathrm{Hg} /$ Fall in SBP $>20 \%$ from baseline value managed with IV fluid initially $(250 \mathrm{ml}$ bolus repeated twice) if required IV Inj. Mephentermine $6 \mathrm{mg}$. Nausea/vomiting with Inj. Ondansetron $4 \mathrm{mg}$ IV. Heavy Sedation (Ramsay sedation score of 4 or more) supplemented with Oxygenation.

Sample size was estimated using the parameter "total duration of sensory blockade." The mean and standard deviation for total duration of sensory blockade in our pilot study was $283.75 \pm 10.3 \mathrm{~min}$ in Group RM and $233.3 \pm 15 \mathrm{~min}$ in Group R. Two-sided confidence interval ( $\alpha$ error $0.05 \%$ ) is $95 \%$ and power of the study ( $\beta$ error $0.1 \%$ ) is $90 \%$ to detect $25 \%$ change in the duration, gives minimum adequate sample size of 30 in each group. For better sensitivity, we include total 80 patients with 40 in each group.

\section{RESULTS}

Statistical analysis was done with SPSS version 15.0. T-test and Chi-square test were used for parametric and non-parametric data, respectively. The results were expressed as mean $\pm \mathrm{SD}$, range or Percentage as relevant. $\mathrm{p}<0.05$ was considered as significant.
Significance of difference among values on intergroup comparison was considered as follows:

- $\mathrm{p}>0.05$ was considered as non-significant

- $\mathrm{p}<0.05$ was considered as significant $\left(^{*}\right)$

- $\mathrm{p}<0.01$ was considered as highly significant $\left({ }^{* *}\right)$

- $\mathrm{p}<0.001$ was considered as very highly significant $(* * *)$.

Demographic parameters were comparable in all the groups (Table 1).

The onset of sensory block was found to be $5.52 \pm 0.87 \mathrm{~min}$ in Group RM whereas in group $\mathrm{R}$ it was $3.35 \pm 0.8 \mathrm{~min}$ with $\mathrm{p}=0.01$. The time for fixation of sensory level was also prolonged in Group RM which was 8.98 \pm 0.9 min whereas in group $\mathrm{R}$ it was $6.78 \pm 0.9$ min with $(* * * p<0.001)$, hence was statistically significant (Fig. 1).

The time taken for sensory regression to T10 dermatome in group RM was $125.5 \pm 4.2$ min significantly prolonged as compared to Group $\mathrm{R}$ which was $103 \pm 10.1 \mathrm{~min}\left({ }^{* * *} \mathrm{p}<0.001\right)$. The total duration of sensory block (regression till S2 level) in Group RM was $242 \pm 9.9$ min whereas in Group $\mathrm{R}$ was $186 \pm 8.4 \mathrm{~min}\left({ }^{* * *} \mathrm{p}<0.001\right)$ and was statistically significant (Fig. 2).

The time to achieve complete motor block was $23.12 \pm 2.7 \mathrm{~min}$ and in group $R$ was $46.12 \pm 4.4$ min with $p=0.5$ which is statistically insignificant but clinically significant. The duration of motor block regression in Group RM was $151 \pm 7.8 \mathrm{~min}$ and in Group R was 184 \pm 5.6 min with $\left({ }^{* * *} \mathrm{p}<0.001\right)$ found to be statistically very significant (Fig. 3).

The $1^{\text {st }}$ time of mobilization after spinal anesthesia was noted to be 170 $\pm 0.1 \mathrm{~min}$ in group RM and $200 \pm 0.4 \mathrm{~min}$ in Group R with $(* * * \mathrm{p}<0.001)$ which was statistically significant (Fig. 4).

The first onset of pain in Group RM was at $725.25 \pm 18.6$ minwhile in Group R was at $425.5 \pm 17.8$ min. ${ }^{* * *} \mathrm{p}<0.001$, hence, was statistically significant (Fig. 5).

The first onset of pain at rest in group RM was at 12 hwith VAS score of $2 / 10$ whereas in group R VAS score was $2 / 10$. The $\left({ }^{* * *} p<0.001\right)$ which was statistically significant (Fig. 6).

The dynamic VAS score at $3 \mathrm{~h}$ in group RM it was $2 / 10$ whereas in Group $\mathrm{R}$ it was $3 / 10$ requiring analgesics. The $(* * \mathrm{p}<0.01)$ which was statistically significant (Fig. 7).

Table 1: Demographic parameters

\begin{tabular}{llll}
\hline Parameters & Group RM $(\mathbf{n = 4 0})$ & Group R $(\mathbf{n = 4 0})$ & $\mathbf{p}$ \\
\hline $\begin{array}{l}\text { Age (years) } \\
\text { (mean } \pm \text { SD) }\end{array}$ & $44 \pm 10.9$ & $45.4 \pm 10.1$ & 0.553 \\
Gender: M/F (n) & $20 / 20$ & $22 / 18$ & 0.65 \\
ASA Grade 1 (n) & 28 & 30 & 0.62 \\
ASA Grade 2 (n) & 12 & 10 & \\
\hline
\end{tabular}

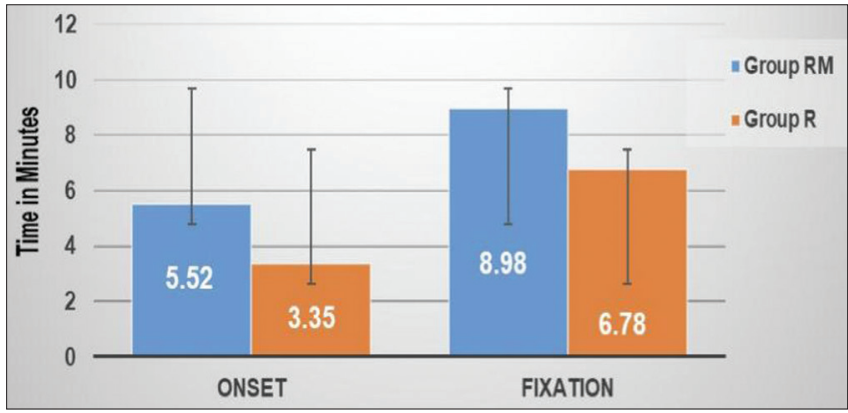

Fig. 1: Sensory block characteristic 


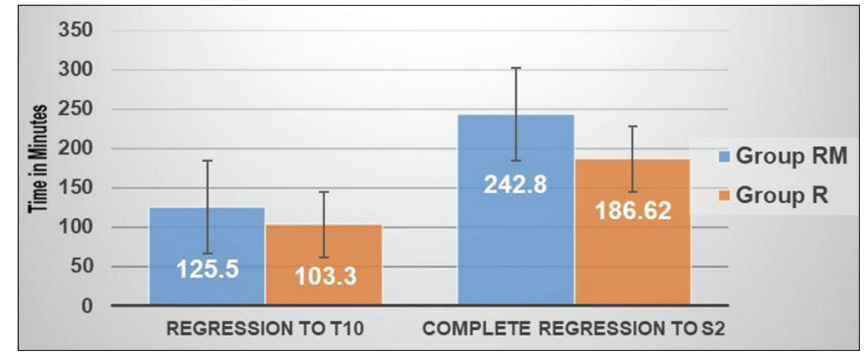

Fig. 2: Duration of sensory block

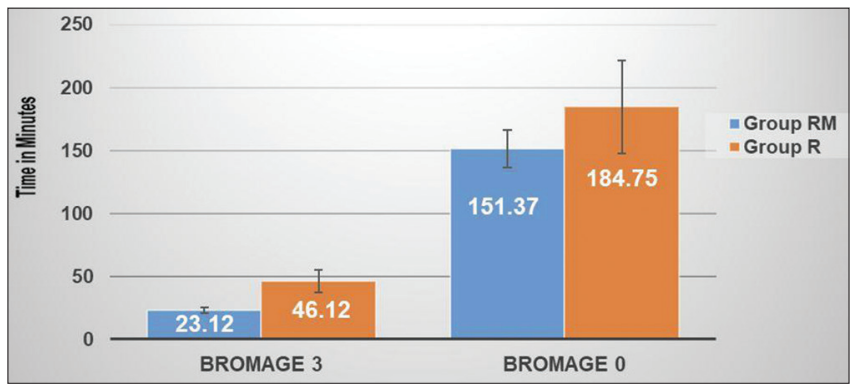

Fig. 3: Motor block characteristic

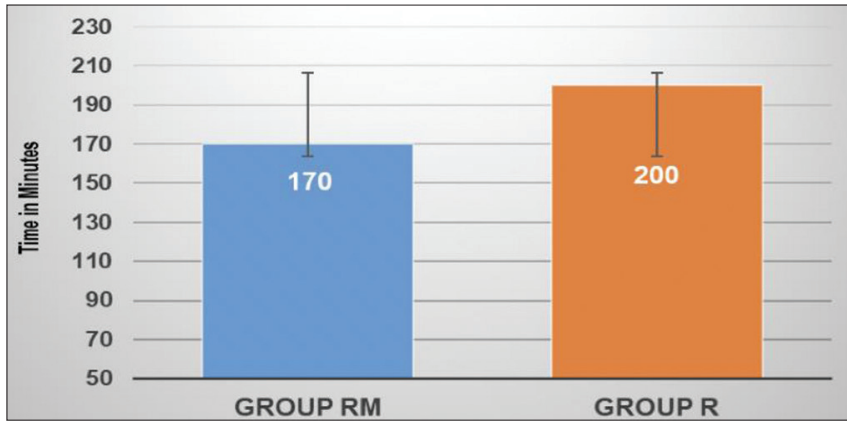

Fig. 4: Time to mobilisation

The total analgesic (Inj. Tramadol) $41.25 \pm 37.3$ milligrams in Group R whereas $172.5 \pm 25.1$ milligram in group $\mathrm{R}$ which was significant with $(* * * p<0.001)$ (Fig. 8).

There was no change from the baseline hemodynamic value in both the groups. All the hemodynamic parameters were within the clinically acceptable range of $\pm 20 \%$ from baseline for the entire duration of surgery in both the groups (Fig. 9).

\section{DISCUSSION}

Magnesium has been proven beneficial in various scenarios beyond its widely accepted role in pre-eclampsia [13]. The safety and efficacy of intrathecal magnesium sulfate has been demonstrated in various human studies [9-11]. Magnesium is a non-competitive N-Methyl D Aspartate (NMDA) receptor antagonist and voltage gated $\mathrm{N}$-type calcium channel blocker. Jabalameli et al. [14] compared three different doses of magnesium sulfate $(50 \mathrm{mg}, 75 \mathrm{mg}$ and $100 \mathrm{mg}$ ) with intrathecal Bupivacaine for infra-umbilical surgeries, concluding that $75 \mathrm{mg}$ of magnesium sulfate prolonged the duration of sensory block and provided adequate post-operative analgesia; without increasing incidence of adverse effects, whereas $50 \mathrm{mg}$ did not provide desired duration and $100 \mathrm{mg}$ produced complications. Hence, we used $75 \mathrm{mg}$ of intrathecal magnesium sulfate with $15 \mathrm{mg}$ of freshly prepared hyperbaric Ropivacaine in our study.

The total duration of sensory block was significantly prolonged in Group RM as compared to Group R ( $240 \pm 9.9$ min vs. $186 \pm 8.4 \mathrm{~min})$

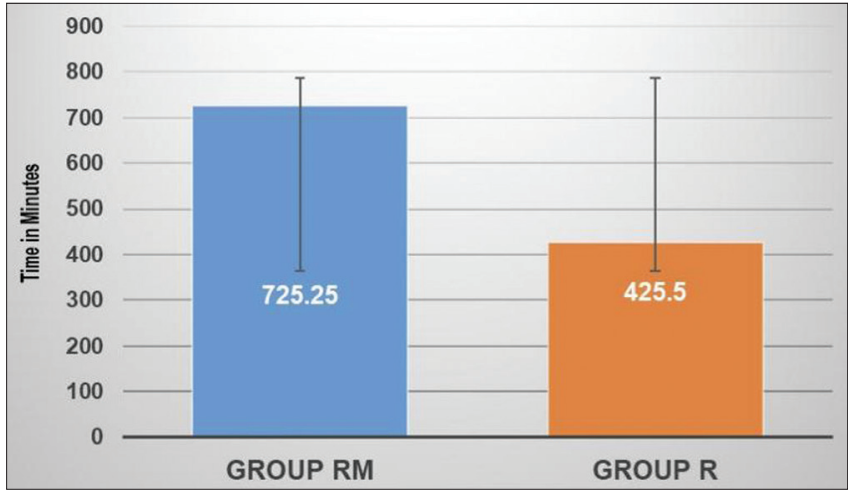

Fig. 5: First onset of pain

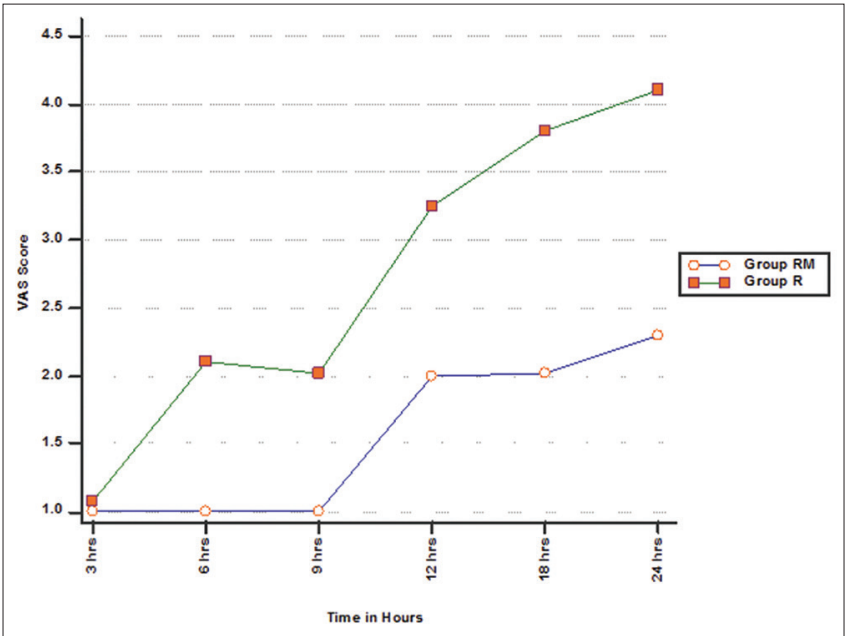

Fig. 6: Static visual analog scale score

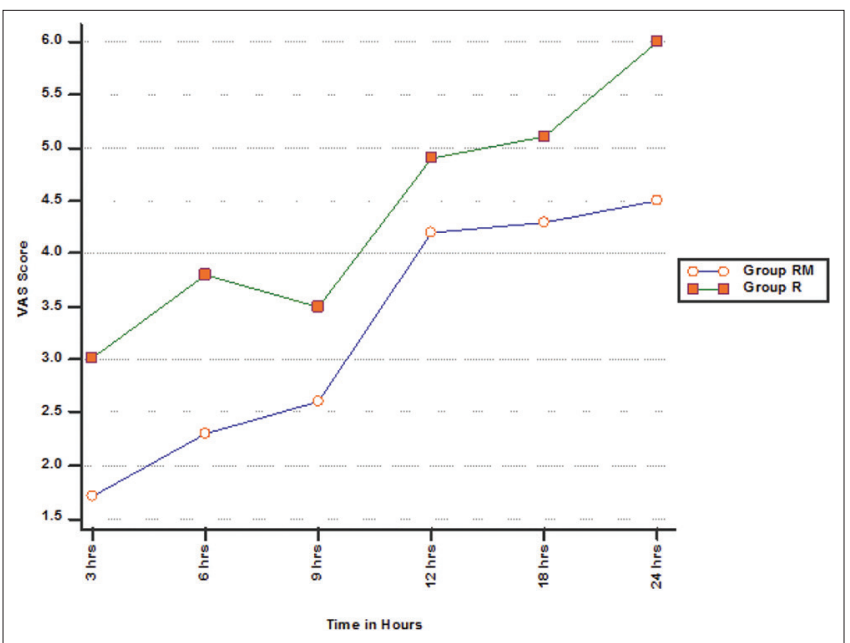

Fig. 7: Dynamic visual analog scale score

$\left({ }^{* * *} \mathrm{p}<0.001\right)$. Group RM showed significantly prolonged duration of clinically useful block (T10 regression time) compared to Group R (125 \pm 4.2 min vs. $103 \pm 10.1 \mathrm{~min})(* * * \mathrm{p}<0.001)$. This is in congruence with studies by Shukla et al. ( $265 \pm 65$ vs. $194 \pm 55 \mathrm{~min}$ ) [15] and Khalil et al. (165.5 vs. $85.5 \mathrm{~min}$ ) [16] who observed significantly prolonged sensory block duration with intrathecal magnesium and local anesthetic; while Unlugenc et al. [17] concluded that $50 \mathrm{mg}$ of magnesium sulfate did not prolong the duration of spinal anesthesia. 


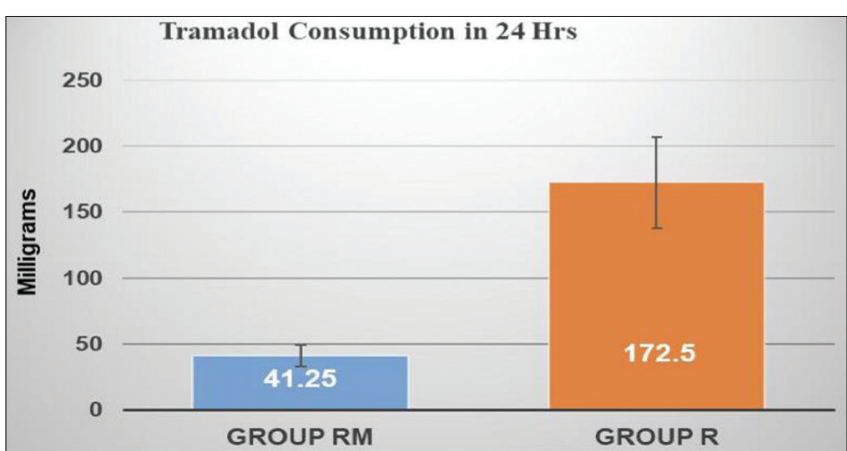

Fig. 8: Analgesic consumption

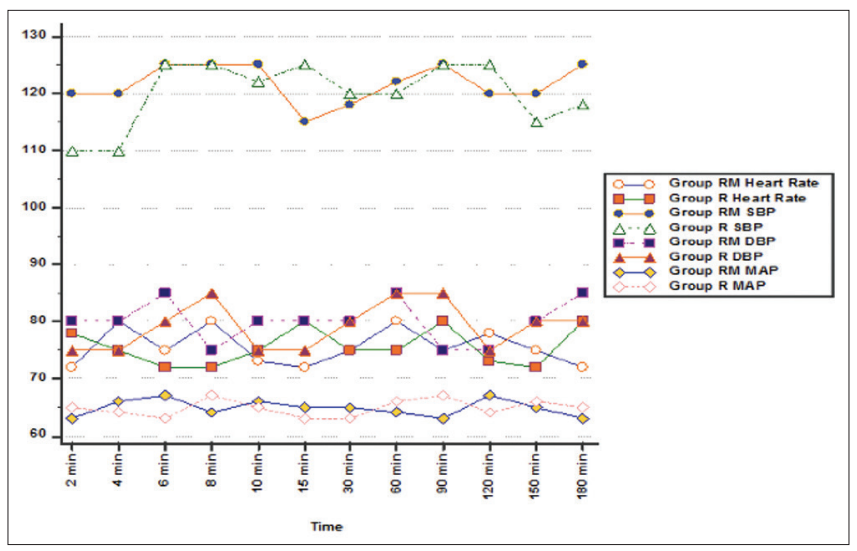

Fig. 9: Hemodynamics

The results of our study showed significantly prolonged sensory block duration in Group RM compared to Group R. Magnesium at larger CSF concentration; it blocks the release of aspartate and glutamate during pain transmission; thereby preventing calcium and sodium influx with potassium efflux [18]. At lower CSF concentration it blocks N-type calcium channel which is densely located in dorsal horn of spinal cord Lamina 1 and 2; and also, its primary afferents (C-fiber and A- delta fiber) which mediates sensation of peripheral noxious stimuli. This inhibits the release of neuropeptides such as substance $\mathrm{P}$ and calcitonin gene related peptide from sensory neurons. This mechanism would not require magnesium ion to synergize with opioid to act as analgesic adjuvant [11].

The mean time of onset for sensory block in group RM was $5 \pm 0.8$ min and in Group R was $3 \pm 0.8 \min \left({ }^{* *} \mathrm{p}<0.01\right)$. The time taken to achieve maximum sensory blockade was $9 \pm 0.9 \mathrm{~min}$ in Group RM and $7 \pm$ 0.9 min in group R $(* * \mathrm{p}<0.01)$. While Morrison et al. [10] observed no clinically significant difference in onset and time to achieve maximum sensory block level with magnesium, the meta-analysis by Ramirez et al. [11] was 2.4 min average difference $\left({ }^{* *} \mathrm{p}<0.001\right)$. Based on the other four studies by Ozalevli et al. [19], Unlugenc et al. [17], Khalil et al. [16], and Shukla et al. [15], the delay in onset was due to modulation in neuronal electrical conduction blockade.

In our study, all the patients achieved sensory level of $\mathrm{T}_{4}-\mathrm{T}_{6}$ level with $3.75 \mathrm{ml}$ of the drug solutions. The higher level achieved probably due to larger volume. Dayioglu et al. [20] similarly reported comparable level of sensory block achieved in both their study groups, with and without magnesium.

The total duration of sensory block was significantly prolonged in Group RM compared to Group R $\left({ }^{* *} p<0.001\right)$. Similarly, Group RM showed significantly prolonged duration of clinically useful sensory block $\left(\mathrm{T}_{10}\right.$ regression time) than Group $\mathrm{R}(* * * \mathrm{p}<0.001)$. Time of onset and fixation of sensory block showed clinically insignificant difference in Group RM and Group R, though it was statistically significant $\left({ }^{* *} \mathrm{p}<0.01\right)$. The motor block onset-time was comparable in both groups $(\mathrm{p}=0.56)$. Group RM patients showed significantly shorter motor block duration than Group R $(* * * p<0.001)$. The pain free interval was significantly higher in Group RM compared to Group R (*** $<<0.001)$. Group RM showed significant reduction in $24 \mathrm{~h}$ post-operative analgesia consumption as compared to Group $\mathrm{R}(\mathrm{p}<0.001)$. Group RM patients mobilized significantly earlier than Group R patients $\left({ }^{*} \mathrm{p}<0.05\right)$.

The duration of motor block in Group RM and Group R was 151 min and 184 min respectively $\left({ }^{*} \mathrm{p}<0.05\right)$. Unlike our study, Shukla et al. concluded significant prolongation of motor block regression with $50 \mathrm{mg}$ magnesium compared to control group $(251 \pm 51 \mathrm{~min}$ versus $140 \pm 34$ min) $(* * * p<0.001)$. While, Morrison et al. [10] demonstrated that magnesium did not prolong the duration of motor blockade $(p=0.21)$. The motor blockade was shorter in Group RM, where earlier mobilization was also observed as compared to Group R. The pain-free interval was significantly prolonged in Group RM which led to lesser analgesia consumption as compared to Group R.

Ambulation with support was possible at $175 \mathrm{~min}$ after spinal anesthesia in Group RM and 200 min in Group R $(* p<0.05)$. Ramirez et al. [11] noted no significant difference in motor recovery with intrathecal Magnesium with 35 min shorter motor block duration in patients without intrathecal magnesium $(\mathrm{p}=0.390)$.

There was no incidence of significant hypotension, bradycardia, heavy sedation, muscle weakness, headache, and respiratory depression in both groups. Morrison et al. [10] reported absence of adverse effects with intrathecal magnesium with the use of $75 \mathrm{mg}$ of intrathecal magnesium sulfate.

The duration of pain-free interval was significantly higher in Group RM compared to Group R (725 min vs. $510 \mathrm{~min}$ ) ( $\left.{ }^{* * *} \mathrm{p}<0.001\right)$. Ramirez et al. [11] also concluded that addition of magnesium sulfate intrathecally with local anesthetic, reduced post-operative analgesia requirement, thus minimizing opioid-induced side effects by favoring usage of oral analgesics, thereby enabling less-intensive monitoring in post-operative period and early "home-readiness" [20]. Magnesium, a noncompetitive NMDA glutamate receptor antagonist, blocks spinally mediated facilitatory component evoked by repetitive C-fiber stimulation through inhibition of slow excitatory post synaptic currents; thus, it can prevent and abolish central sensitization [11].

Bamigbade et al. [21] showed that tramadol was effective analgesic for providing post-operative pain relief. In our study, the total 24-h postoperative analgesia consumption was significantly lesser in Group RM compared to Group R (42.5 mg vs. $172.5 \mathrm{mg}$ ) (*** $<0.001)$. This reduction in post-operative analgesia consumption with magnesium as intrathecal adjuvant is due relatively slow binding and dissociation of NMDA antagonists [22], thereby extending its analgesic effects into post-operative period.

We used Dip stick method to estimate specific gravity of spinal anesthetic solution as densitometer was not available. They were found within comparable range of 1.025-1.030.

\section{CONCLUSION}

We conclude that magnesium sulfate as an intrathecal adjuvant since it safely prolonged the duration of sensory blockade, pain free interval. The onset time of sensory and motor block was clinically insignificant. It did not prolong the duration of motor blockade. Patients' satisfaction was enormous in terms of ability to move their limbs and walk with support for their needs within few hours post-surgery without pain; hence, magnesium sulfate as an adjuvant to hyperbaric ropivacaine is an excellent combination for day care procedures. It reduced postoperative analgesia consumption. It has shown no incidence of adverse or untoward hemodynamic variations hence can be considered advantageous for day care surgeries. 


\section{AUTHORS CONTIBUTION}

1. Srinidhi Srikanth: Data collection, Analysis and Concept in part.

2. Antony John Charles S: Concept, Ideas, Design, Supervision, Writing, and Communication.

3. Yasha Kamaeshar: Concept in part.

4. Gayatri Mishra: Concept in part.

\section{CONFLICTS OF INTEREST}

Nil for each Author.

\section{FUNDING}

Nil.

\section{REFERENCES}

1. Kuthiala G, Choudhary G. Ropivacaine: A review of its pharmacology and clinical use. Indian J Anaesth 2011;55:104-10.

2. Fettes PD, Hocking G, Peterson MK, Luck JF, Wildsmith JA. Comparison of plain and hyperbaric solutions of ropivacaine for spinal anaesthesia. Br J Anaesth 2005;94:107-11.

3. Singh AP, Kaur R, Gupta R, Kumari A. Intrathecal buprernorphine versus fentanyl as adjuvant to $0.75 \%$ ropivacaine in lower limb surgeries.J Anaesthesiol Clin Pharmacol 2016;32:229-33.

4. Campora E, Merlini L, Pace M, Bruzzone M, Luzzani M, Gottlieb A, et al. The incidence of narcotic-induced emesis. J Pain Symptom Manage 1991;6:428-30.

5. Haubold HA, Meltzer SJ. Spinal anaesthesia by magnesium sulphate. A report of seven operations performed under its influence. J Am Med Assoc 1906;46:647-50

6. Herroeder S, Schönherr ME, De Hert SG, Hollmann MW. Magnesiumessentials for anaesthesiologists. Anaesthesiology 2011;114:971-93.

7. James MF. Magnesium: An emerging drug in anaesthesia. Br J Anaesth 2009; 103:465-7.

8. Do SH. Magnesium a versatile drug for anaesthesiologists. Korean J Anesthesiol 2013;65:4-8

9. Buvanendran A, McCarthy RJ, Kroin JS, Leong W, Perry P, Tuman KJ. Intrathecal magnesium prolongs fentanyl analgesia: A prospective, randomized, controlled trial. Ansesth Analg 2002;95:661-6.

10. Morrison AP, Hunter JM. Halp: Effect of intrathecal magnesium in the presence or absence of local anesthetic with and without lipophilic opioids: A systematic review and metanalysis. Br J Anesth 2013;13:702-12.

11. Ramirez JP, Trujillo SG, Alcantarilla C. Intrathecal magnesium as analgesic adjuvant for spinal anesthesia: A meta-analysis of randomized trials. Min Anestesiol 2013;79:667-78.

12. Kulkarni KR, Deshpande S, Namazi I, Singh SK, Kondilya K. A comparative evaluation of hyperbaric ropivacaine versus hyperbaric bupivacaine for elective surgery under spinal anesthesia. J Anesthesiol Clin Pharmacol 2014;30:238-42.

13. Jabalameli M, Pakzadmoghadam SH. Adding different doses of intrathecal magnesium sulphate for spinal anesthesia in the cesarean section: A prospective double blind randomized trial. Adv Biomed Res 2012;1:7.

14. Jabalameli M, Hamid S, Pakzadmoghadam: Adding different dose of intrathecal magnesium sulphate for spinal anesthesia for caesarean section. Adv Biomed Res 2012;1:1

15. Shukla D, Verma A, Agarwal A, Pandey HD, Tyagi CH. Comparative study of intrathecal dexmedetomidine with intrathecal magnesium sulphate used as adjuvants to bupivacaine. J Anaesthesiol Clin Pharmacol 2011;27:495-9.

16. Khalil G, Janghorbani M, Sajedi P, Ahmadi G. Effects of adjunct intrathecal magnesium sulphate to bupivacaine for spinal anaesthesia: A randomized, double-blind trial in patients undergoing lower extremity surgery. J Anaesth 2011;25:892-7.

17. Unlugenc H, Ozalevli M, Gunduz M, Gunasti S, Urunsak F, Guler T, et al. Comparison of intrathecal magnesium, fentanyl, or placebo combined with bupivacaine $0.5 \%$ for parturients undergoing elective cesarean delivery. J Acta Anaesthesiol Scand 2009;53:346-53.

18. Woolf CJ, Thompson SW. The induction, maintenance of central sensitization is dependent on N-methyl-D-aspartic acid receptor activation implication for the treatment of post-injury pain hypersensitivity states. Pain 1991;44:293-9.

19. Ozalevli M, Cetin TO, Unlugenc H, Guler T, Isik G. The effect of adding intrathecal magnesium sulphate to bupivacaine-fentanyl spinal anaesthesia. Acta Anaesthesiol Scand 2005;49:1514-9.

20. Dayioglu H, Baykara ZN, Sabes A, Solak M, Toker K. Effects of adding magnesium to bupivacaine and fentanyl for spinal anaesthesia in knee arthroscopy. J Anaesth 2009;23:19-25.

21. Bamigbade TA, Langford RM, Blower AL. Pain control in day care surgery; tramadol compared to standard analgesia. $\mathrm{Br} \mathrm{J}$ Anaesth 1998;80:558-9.

22. Ascher P, Norwak L. Electrophysiological studies of NMDA receptor. Trends Neurosciences 1987;10:284-8. 